\title{
The impact of a very weak and thin upper asthenosphere on subduction motions
}

\author{
R. Carluccio ${ }^{1,2,3 *}$, B. Kaus ${ }^{2}$, F. A. Capitanio ${ }^{4}$, L. N. Moresi ${ }^{1,5}$ \\ ${ }^{1}$ School of Earth Sciences, University of Melbourne, Melbourne, VIC, AU. \\ ${ }^{2}$ Institute of Geosciences, Johannes Gutenberg University Mainz, Mainz, DE. \\ ${ }^{3}$ Department of Geosciences, University of Padua, Padua, IT. \\ ${ }^{4}$ School of Earth, Atmosphere and Environment, Monash University, Clayton, VIC, AU \\ ${ }^{5}$ Research School of Earth Sciences, Australian National University, Canberra, ACT, AU
}

\begin{abstract}
Key Points:
- Numerical models show that a very weak and thin upper asthenosphere layer can alone reduce trench retreat and enhance plate motion

- The impact of this effect depends on the relative contrast between the effective stiffness of the lithosphere and the underlying mantle

- This regional mechanism explains the high convergence and low trench migrations rates observed globally at natural subduction zones
\end{abstract}

\footnotetext{
${ }^{*}$ School of Earth's Science, University of Melbourne, Melbourne, VIC, AU

Corresponding author: Roberta Carluccio, rcarluccio@student.unimelb.edu.au
}

This is the author manuscript accepted for publication and has undergone full peer review but has not been through the copyediting, typesetting, pagination and proofreading process, which may lead to differences between this version and the Version of Record. Please cite this article as doi: 10.1029/2019GL085212 


\begin{abstract}
Recent geophysical observations report the presence of a very weak and thin upper asthenosphere underneath subducting oceanic plates at convergent margins. Along these margins, trench migrations are significantly slower than plate convergence rates. We use numerical models to assess the role of a weak upper asthenospheric layer on plate and trench motions. We show that the presence of this layer alone can enhance an advancing trend for the motion of the plate and hamper trench retreat. This mechanism provides a novel and alternative explanation for the slow rates of trench migration and fast-moving plates observed globally at natural subduction zones.
\end{abstract}

\title{
Plain Language Summary
}

Plate tectonics relies on the concept of a rigid surface layer (the lithosphere) fragmented in a series of major and minor tectonic plates moving over a weaker and buoyant layer of asthenospheric material. The motion and deformation of the lithosphere are primarily driven by the sinking of the colder and denser oceanic lithosphere through time into the Earth's interior at subduction zones. A range of geophysical regional studies has recently brought considerable attention to the detailed structure of the asthenosphere at these zones. These studies report the presence of a thin and even weaker asthenospheric layer at the base of the subducting lithosphere. We investigate the role of this layer on subduction dynamics using geodynamics numerical models. Our models apply knowledge of physics, chemistry, mathematics and geology, and study the dynamics of the Earth's deep interior and their feedback on surface deformation. Our numerical results demonstrate that a very weak and thin upper asthenosphere affects the dynamics of sinking plates. It acts as a slippery base for the motion of the plate significantly increasing its speed and deformation. Our research provides a novel explanation to interpret some of 
the subduction phenomena at the regional scale observed on Earth, which have proven numerical difficulties until now.

\section{Introduction}

The boundary between the Earth's tectonic plates and the underlying mantle, the lithosphere-asthenosphere boundary (LAB), is a fundamental element of plate tectonics as it critically controls the mechanical coupling between the motion of the tectonic plates and the flow in the underlying mantle (Anderson, 1995). The motions and deformation of the solid plates are primarily driven by the downward pull of slabs (Harper, 1975; Forsyth et al., 1975; Chapple \& Tullis, 1977; Conrad \& Lithgow-Bertelloni, 2002) and by the coupling with the viscous mantle flow surrounding them (Lithgow-Bertelloni \& Richards, 1995, 1998; Conrad \& Hager, 1999; Becker \& O'Connell, 2001). Forces associated with the sinking of slabs into the mantle propagate to the surface controlling plate motions towards the trench zone and mantle flow around subducting slabs. Therefore, a very weak and thin upper asthenosphere (WL) may contribute to the drag exerted at the base of subducting plates having an impact on the force balance around the oceanic lithosphere. This could play an important role in decoupling the motion of tectonic plates from the flow in the underlying mantle, promoting or opposing subduction motions with respect to the mantle underneath.

The subduction of an oceanic plate into the mantle occurs concurrently with the motion of trenches at the surface. These are mobile and can either retreat, advance, or have a mixed type of motion in time with respect to a specific reference frame. We refer to the percentage ratio between the horizontal plate $\left(V_{\mathrm{P}}\right)$ and trench migration $\left(V_{\mathrm{T}}\right)$ velocities as the subduction partitioning $\left(V_{\mathrm{T}} / V_{\mathrm{P}}\right)$. The subduction partitioning, as well as the subduction dip angle and the morphology assumed by the subducting slab while interacting with the $660 \mathrm{~km}$ transition zone are considered diagnostic elements to iden- 
tify the subduction style (e.g., Christensen, 1996; Zhong \& Gurnis, 1997; Bellahsen et al., 2005; F. Capitanio et al., 2007; Faccenna et al., 2007; Di Giuseppe et al., 2008; Funiciello et al., 2008; F. A. Capitanio et al., 2009; Stegman et al., 2010; Goes et al., 2011; Gérault et al., 2012). Most of the Earth's slab and trench motions occur in conjunction with roll-back and retreat $\left(-V_{\mathrm{T}}\right)$, however advancing plate and trench motion $\left(+V_{\mathrm{T}}\right)$ towards the upper plate can also be found in some trench zones, e.g. at some of the edges of the Pacific plate (Schellart et al., 2008). Furthermore, the average absolute trench velocity observed globally is one third or less of the total convergence at the present, consistently across the majority of plate motions reference frames (e.g., Elsasser, 1971; Jarrard, 1986; Schellart et al., 2008; Becker \& Faccenna, 2009; A. F. Holt \& Becker, 2016; Goes et al., 2011). Numerical and analogous subduction models have previously helped explain the fundamental force balance of plate motions, yet the observed slow retreat with fast advance does not emerge as a general feature (A. F. Holt \& Becker, 2016; Coltice et al., 2017). Geoid observations (Moresi \& Gurnis, 1996; Mitrovica \& Forte, 1997; Zhong \& Davies, 1999), and numerical and geophysical studies (e.g., Schellart, 2004; Bellahsen et al., 2005; Di Giuseppe et al., 2008; Funiciello et al., 2008; Schellart et al., 2008; Wu et al., 2008; F. A. Capitanio et al., 2009) constrain the viscosity contrast between the subducting oceanic plates and the mantle to be within a range of 100-500. These show significant slab roll back and trench retreat (i.e. $\left.V_{\mathrm{T}} / V_{\mathrm{P}}<-0.3\right)$. In most of these models, trench advance occurs for stiff, slowly migrating plates such as those with a viscosity contrast between the subducting lithosphere and the mantle greater than 1000. However, this is not easily reconciled with what is generally observed in nature and might apply to regional cases only (e.g., Jarrard, 1986; Garfunkel et al., 1986; Lallemand et al., 2005; Bellahsen et al., 2005; Sdrolias \& Müller, 2006; Faccenna et al., 2007; Funiciello et al., 2008; Schellart et al., 2008; Di Giuseppe et al., 2008; Stegman et al., 2010; Goes et al., 2017). This still presents the difficult task of explaining the low apparent strength of tectonic plates relative to the 
underlying mantle and the efficient slab pull propagation needed in subduction models to match plate velocities. Some solutions to explain such a slow retreating motion have been proposed,such as the role of slab rheology (e.g., F. Capitanio et al., 2007; Billen \& Hirth, 2007; F. A. Capitanio et al., 2009) or a complex mantle rheology (e.g., A. F. Holt \& Becker, 2016), the effect of slab and trench widths (e.g., Schellart et al., 2007, 2010), the presence of an overriding plate (e.g., Rodríguez-González et al., 2012; A. F. Holt et al., 2015), multiple plates (e.g., Yamato et al., 2009) or slabs (e.g., Faccenna et al., 2017; A. Holt et al., 2017), the effect of the interaction between the slab and the upper/lower mantle discontinuity (e.g., Goes et al., 2008; Garel et al., 2014; Yang et al., 2017; Billen \& Arredondo, 2018) and the effect of ridge push and a low viscosity asthenosphere (e.g., F. Capitanio et al., 2007; Stegman et al., 2010).

Some of these studies (i.e., F. Capitanio et al., 2007; A. F. Holt \& Becker, 2016; Billen \& Arredondo, 2018) have also provided insights into how an asthenosphere of diverse origin could diminish trench retreat rates. However, the globally observed trend in trench and plate motions and their partitioning at subduction zones is yet to be investigated, especially in light of the recent geophysical observations of a very weak and thin upper astenosphere (Kawakatsu et al., 2009; Schmerr, 2012; Naif et al., 2013; Stern et al., 2015; Hawley et al., 2016). Common to all these observations is the evidence of a seismic velocity drop (5 to 10\%) across a sharp boundary, no more than 30km thick, at base of the subducting lithosphere at different locations in the Pacific plate. The presence of this layer, which may support the theory of a plume-fed asthenosphere (e.g., Morgan, 1971, 1972; Phipps Morgan et al., 1995), is attributed to a significant number of volatiles and/or hydrated mantle phases. These are thought to have lowered density and viscosity, increasing the partial melt fraction, and resulting in partial melt "ponded" in lenses or channels at the base of the oceanic lithosphere (e.g., Schmerr, 2012; Sakamaki et al., 2013; Haw- 
ley et al., 2016). Furthermore, at these localities, we generally observe $\left|V_{\mathrm{T}} / V_{\mathrm{P}}\right|<$ $\frac{1}{3}$, which applies in the majority the reference frames (Schellart et al., 2008; Goes et al., 2017; Coltice et al., 2017). A thin layer with a high fraction of partial melt is expected to have significantly reduced mechanical strength that could potentially decouple plate motions from mantle tractions and strongly influence the force balance between slabs, plate and the mantle.

Previous global numerical models (i.e. Lithgow-Bertelloni \& Richards, 1995; Bercovici, 1996; Zhong et al., 1998; Tackley, 2000; F. Capitanio et al., 2007; F. A. Capitanio et al., 2009; Stegman et al., 2010; Höink et al., 2011, 2012; Gérault et al., 2012; Goes et al., 2017; Becker, 2017) analyzed the role of a low viscosity asthenosphere (LVZ) but only a few have accounted for an LVZ of a limited thickness within the range of 100-200km (Becker, 2017; Richards \& Lenardic, 2018; Semple \& Lenardic, 2018). Generally, an asthenosphere seems to better characterize plate-like behaviour improving our ability to match with observed surface velocities (Tackley, 2000; Gérault et al., 2012). Interestingly, a thinner LVZ with a stronger viscosity contrast shows to further promote plate motions leading to a stress magnification at the base of the lithosphere and helping overcome the viscous resistance at the base of the lithosphere (Richards \& Lenardic, 2018). However, this has also shown to have a smaller effect on the global net rotation and observed global seismic anisotropy, as well as on global plate and subduction velocities, where large-scale plate dynamics seem most likely governed by broad continent-ocean asthenospheric viscosity and buoyancy contrasts (e.g., F. Capitanio et al., 2007; Goes et al., 2017; Becker, 2017).

On the other hand, if an LVZ seems to have a negligible effect on the large-scale subduction dynamics or represents a global feature, a very thin and weak top asthenosphere could still play a fundamental role for deciphering some of the observations of subduction partitioning at the regional scale, and provide relevant insights on global subduction zones on Earth. Such as those 
dominated by fast-moving plates and slow migrating trenches, which have proven numerically difficult until now. Yet, the role of a very thin $\left(h_{W L} \sim 10-100 \mathrm{~km}\right)$ and weak $\left(\eta_{W L} / \eta_{W L} \sim 10-1000\right) \mathrm{WL}$ on the subduction partitioning $\left(V_{\mathrm{T}} / V_{\mathrm{P}}\right)$ has remained unexplored to date. Here we aim to address the impact of a WL on trench and plate velocities and their partitioning at subduction zones. Additionally, our work builds upon on the recent geophysical inferences of a very weak and thin upper asthenosphere at convergent margins in the Pacific plate. We use a series of numerical experiments carried out in 2D to investigate the impact of a WL on the velocity and morphology of subducting slabs, adopting the geological and geophysical constraints described above. We then discuss the inferences these models yield on subduction dynamics.

\section{Method}

To investigate the role of a WL on subduction dynamics, we use the numerical code Underworld, described in detail by Moresi et al. (2007) and Stegman et al. (2006). The code follows a continuum mechanics approximation, which is widely used to describe geological and geophysical processes, and solve the conservation equations of mass, momentum and energy. We assume incompressibility and neglect temperature diffusion.

The initial model setup follows the approach of Schmeling et al. (2008); Yamato et al. (2009); Enns et al. (2005) and is adapted to solve the problem under investigation. We model subduction dynamics and mantle flow in a Cartesian box that extends $4000 \mathrm{~km}$ in the horizontal $(\mathrm{X})$ direction and $660 \mathrm{~km}$ in depth (Y). Our models are made of 4 layers. There is an oceanic crust, an oceanic plate, a weak upper asthenospheric layer and an underlying mantle, as shown in figure 1b. Although similar, this setup differs from previous studies (e.g., Schellart et al., 2007; Stegman et al., 2006) because the oceanic plate is made of one single layer and the WL is characterized by a lower viscosity value than in the underlying asthenosphere or deeper mantle. The initial condition for 
the subducting plate includes an initial trench position 1000km away from the wall and a slab tip already penetrating the mantle, $257 \mathrm{~km}$ deep with a dip angle of $34^{\circ}$ to the horizontal. The modelled WL is located at the base of the oceanic plate and extends underneath the whole length of the oceanic plate, and has a thickness of $30 \mathrm{~km}$. We use a model domain of $256^{*} 128$ elements with a uniform grid spacing in each coordinate direction. This ensures sufficient numerical resolution to promote and properly-resolve the development of a weak hinge zone. Our 2-D experiments use a pseudo-plastic (PP) constitutive law with visco-plastic rheology near the surface and a Newtonian formulation deeper into the lithosphere and mantle. The visco-plastic rheology of the crust promotes the development of a weak hinge zone, which simulates the free surface and enables the oceanic lithosphere to detach from the top surface of the model and subduct freely into the mantle (Schmeling et al., 2008; Crameri et al., 2012). Plasticity is implemented through a depth-dependent yield criterion (Moresi \& Solomatov, 1998). We use a cohesion of a 20MPa, a friction angle of 30 degrees and a density contrast between the oceanic lithosphere and the underlying mantle of $80 \mathrm{~kg} / \mathrm{m}^{3}$. The visco-plastic crustal layer controls the kinematics (Enns et al., 2005; Royden \& Husson, 2006); however, the description of this phenomena is outside the scope of this study. The velocity boundary conditions are free-slip everywhere to minimize the influence of the box sidewalls (a free-slip condition means no tangential stress and zero normal velocity). We do not apply any kinematic boundary and subduction is thus dynamically initiated. The reliability of the model has been tested against previous work as shown in section 3 . The assigned values result in subduction velocities of 10-2 cm/yr in line with the average values predicted on Earth (figure 1c, 2 and 3).

We aim to identify end-member cases that support the description of the mechanical effect of a WL at the LAB on a subduction zone. For this goal, we use a simplified rheological and geometrical model. This very setup is nec- 
essary to constrain only the impact of a WL and to prove that subduction motions can be the result of a simple force balance around subducting plates, while no external forces are needed. In our study, we vary the properties of the WL at the base of the oceanic lithosphere, i.e. its viscosity, density and thickness. Additionally, we also explore the effects of different viscosity and thickness contrast between the plate and the mantle, and the effect of the crustal friction angle. A small number of more complicated models explores the extent to which these simplifications may influence our conclusions, such as the use of a more realistic visco-elastic-plastic temperature ( $\mathrm{T}$ )-dependent rheology (VEP) with and without a WL. Finally, we omit the study of the mechanical effects given by variation in buoyancy of plates, as these are well documented in the literature (e.g., Christensen, 1996; Bellahsen et al., 2005; Faccenna et al., 2007; F. Capitanio et al., 2007; Funiciello et al., 2008; Di Giuseppe et al., 2008; F. A. Capitanio et al., 2009; Stegman et al., 2010; Goes et al., 2011; Gérault et al., 2012).

The type of flow in the asthenosphere can promote or resist plate motions with respect to the underlying mantle. This flow can be driven by the plates themselves (Couette flow), pressure driven by the flow within the mantle (Poiseuille flow) or a combination of the two (combined Couette-Poiseuille flow). Several authors (e.g., Conrad \& Hager, 1999; N. M. Ribe, 1992; N. Ribe, 2001; N. M. Ribe, 2010; Buffett \& Becker, 2012; Stegman et al., 2010; Gerardi \& Ribe, 2018; Semple \& Lenardic, 2018; Gerardi et al., 2019) hat the force balance of the oceanic lithosphere is controlled by the balance of both bendingstretching momentum and boundary and internal stresses (flow in the boundary layer).

Among these authors (i.e., N. M. Ribe, 1992; N. Ribe, 2001; Gerardi \& Ribe, 2018; Richards \& Lenardic, 2018; Gerardi et al., 2019) show that the motion of a mantle fluid in an interface layer, can be approximated with the motion of a Stokes fluid in the lubrication limit. This procedure is valid when 
the thickness of the layer is much thinner than the horizontal length, if $l_{\mathrm{WL}} / h_{\mathrm{WL}}$ $\ll 1$. An approximation of the tangential forces representing the motion of a Stokes's fluid in a thin layer in the lubrication limit led to the definition of the dimensionless stiffness of a surface shell (N. M. Ribe, 1992; N. Ribe, 2001) and an interface layer (Gerardi \& Ribe, 2018; Gerardi et al., 2019). In our study, we are interested in describing the deformation in the effective lithosphere relative to the underlying mantle, which may or may not contain a WL on the partitioning of trench and plate motions. Based on our numerical experiments, we represent a first order approximation of the deformation occurring in the system (with and without a WL) using a series of parameters related to the dimensionless stiffness of the effective lithosphere.

We empirically find that the effective relative strength, $S^{\prime}$, and thickness, $h^{\prime}$, of the lithosphere relative to the underlying mantle (figure $3 \mathrm{a}$ and $\mathrm{b}$, and figure 7SI in the supporting information) can be taken into account as:

$$
S^{\prime}=\frac{\eta_{\mathrm{P}} \eta_{\mathrm{WL}}}{\eta_{\mathrm{M}}^{2}}, \quad h^{\prime}=\frac{h_{\mathrm{P}}}{h_{\mathrm{M}}}\left(1+\frac{h_{\mathrm{WL}}}{h_{\mathrm{M}}}\right)
$$

where $\eta_{\mathrm{P}}, \eta_{\mathrm{WL}}$ and $\eta_{\mathrm{M}}$ indicate the viscosity of the plate, weak layer and mantle, and with $h_{\mathrm{P}}, h_{\mathrm{WL}}$ and $h_{\mathrm{M}}$ being thicknesses of the plate, the WL and the mantle respectively. Note that when a WL is not included $\eta_{\mathrm{WL}}=\eta_{\mathrm{M}}$ and $h_{\mathrm{WL}}=0$, allowing us to characterise all the experiments with and without a WL.

We also find that the combined effect of the relative contrast in strength and thickness between the effective lithosphere and the underlying mantle can be expressed by the effective relative stiffness of the lithosphere, $D^{\prime}$, as:

$$
D^{\prime}=\log \left(S^{\prime}\right) h^{\prime}
$$


D'represents an approximation of the tangential forces acting on a subducting lithosphere (with and without a WL) and help to explain the decoupling effect of a WL at the base of the lithosphere. Our study represents a balance of forces problem where the subduction dynamics with a WL are governed by the balance of bending-stretching moment and internal and boundary stresses (flow in the lithosphere and asthenosphere), which controls dip and curvature of slabs, figure 3c, providing new insights on the partitioning of subduction surface motions.

Further in the text, these parameters are used to describe the deformation occurring in the system. Finally, in our simulations we refer to $V_{O P}$ as the magnitude of the horizontal plate velocity and $V_{T}$ as the trench migration velocity. The results obtained in our numerical simulations were systematically analysed, particularly through the analysis of the morphological and velocity fields through time evolution of the models. More information about the methodology adopted and the parameters used and varied in this study is available in the supporting information.

\section{Results}

Here, we firstly present the evolution and general aspects of the reference model (RM), which satisfy a range of geophysical and geological observations, then summarize the results obtained for all the subduction experiments in comparison to the RM case. Also, all the PP models presented here share three common subduction temporal evolution stages. These evolution stages are: (i) an initial period where subduction is dynamically initiated and the slab progressively accelerates while is sinking into the mantle; (ii) a transitional stage where the slab decelerates while interacting with the bottom of the model; and (iii) a final steady-state configuration at the mid-mantle boundary. These are shown in figure $1 \mathrm{C}$ and 2 , and are in agreement with pre- 
vious studies (e.g., Bellahsen et al., 2005; Yamato et al., 2009; Stegman et al., 2010).

\subsection{Reference model evolution}

The reference model has the same characteristic of the model setup presented above, but it does not contain a WL (figure 1Aa). The temporal evolution of this model is shown in figure $1 \mathrm{Ca}, \mathrm{b}$, and c. As the model progresses in time, we distinguish three stages of evolution given by the sinking of the oceanic plate into the mantle. In the first stage, the initiation of subduction follows the initial buoyancy configuration, with a slab tip immersed in the mantle. During this stage, the slab reaches a dipping angle of $60-70^{\circ}$ and the magnitude of the plate velocity increases progressively. This stage is associated with trench retreat at the surface, while at depth, the progressive sinking drives a displacement of the mantle from beneath the slab (figure $1 \mathrm{Ca}$ ). In the second phase, the slab tip interacts with the bottom of the model box. This phase is reached in 9.23 million years and is characterized by a general velocity drop (figure $1 \mathrm{Cb}$ ). The final stage is defined by the sliding of the slab at the bottom of the model and the system reaches an approximate steady-state configuration (figure $1 \mathrm{Cc}$ ). During this stage, the plate velocity increases toward an intermediate value between the two previous time phases and the slab continues to roll back while the trench retreats (figure 2a, b). Since the reliability and the evolution of this model are well known and in agreement with the literature (e.g., Bellahsen et al., 2005; Funiciello et al., 2008), it was chosen as a reference for comparison with the models having a WL.

\subsection{An advancing trend for plate and trench motions.}

The primary effect of introducing a weak upper asthenospheric layer is to increase the subduction speed, particularly increasing plate convergence velocity and reducing trench retreat motion. In some models, it also increases 
the subduction dip angle and influences the shape assumed by the subducting slab, while interacting with the $660 \mathrm{~km}$ discontinuity (figure $1 \mathrm{C}$ and 3 ). A comparison between the RM and a WL model having a viscosity contrast between the mantle and the WL of 2 order of magnitude $\left(\eta_{\mathrm{M}} / \eta_{\mathrm{WL}}=10^{2}\right)$ shows these effects in figure $1 \mathrm{Ca}, \mathrm{b}, \mathrm{c}$ and $1 \mathrm{Cd}, \mathrm{e}, \mathrm{f}$, respectively.

The impact of these effects depends mainly on the viscosity between the mantle and the WL and on the thickness of the WL, and less on the density of the WL. In our PP models, we find that for moderate viscosity contrasts mantle-WL $\left(10^{1}<\eta_{\mathrm{M}} / \eta_{\mathrm{WL}}<10^{2}\right)$ and a layer thickness between $10-20 \mathrm{~km}$, $V_{P}$ increases and trench retreat rate decreases, while the overall shape of the slab is not substantially affected. However, for larger viscosity contrasts $\left(\eta_{\mathrm{M}} / \eta_{\mathrm{WL}}\right.$ $\left.\geq 10^{2}\right)$ and thickness of the weak layer $(>20 \mathrm{~km})$, a significant change in velocity and trench migration mechanism develops and, the morphology of the subducting slab may also change (figure 2$)$. For thinner $\left(h_{\mathrm{WL}}<10 \mathrm{~km}\right)$, more buoyant $\left(\Delta r h o_{(\mathrm{M}-\mathrm{WL})} \approx 20\right)$ and stronger layers $\left(\eta_{\mathrm{M}} / \eta_{\mathrm{WL}} \leq 10\right)$, the overall effect is reduced. However, thinner layers are sensitive to numerical resolution and, it is plausible that thinner layers may also play a relevant role on the $V_{T} / V_{P}$. It is also important to note that a WL has not a significant impact on the time necessary for the slab tip to reach the bottom of the model (figure $2 \mathrm{c}$ and $\mathrm{f}$ ), which shows that a WL has a smaller influence on the vertical slab motion than it has on the horizontal plate motion.

All models with a WL show a significantly steeper velocity transition at the base of the lithosphere compared with models with no WL (figure 1C). This suggests that a weak and thin upper asthenosphere has the potential to effectively decouple the motion of the lithosphere from the flow into the underlying mantle. This process results in a more efficient asthenosphere drag, which decreases the resistance to shearing in the underlying mantle, lubricates the base of a plate and in turn contributes to increasing the plate speed (figure $1 \mathrm{C}$ and figure $2 \mathrm{a}, \mathrm{b}, \mathrm{d}$ and e). The WL acts as a slippery base for the mo- 
tion of the oceanic plate while sinking into the mantle. Since a WL is lighter than the above lithosphere (Kawakatsu et al., 2009; Hawley et al., 2016), also the rising of lighter material contributes to the gravitational sliding of the plate (figure 1C). Furthermore, the deep entertainment of a WL on one side of the subducting slab also reduces the viscous drag and thus, facilitates the sinking of the slab into the mantle. Such vanishing drag on one of the slab's sides justifies the increase in sinking velocities up to a factor of $\approx 2$ we observe in our models, (figure 1C and 2a and d).

In our models, we also observe a correlation between the value of the subduction partitioning and the effective relative strength, $S^{\prime}$, and the inverse of the thickness, $1 / h^{\prime}$, of the lithosphere, as shown in figure 3a and b. Three important features are worth noting. First, this trend can be described by an inverse-tangent function for both $S^{\prime}$ and $1 / h^{\prime}$. Second, for low and high values of $S^{\prime}$ and $1 / h^{\prime}$, the subduction partitioning doesn't change significantly and the function trend is asymptotic. Hence a WL can increase plate velocities value up to a maximum of a factor of $\approx 2$ and oppose trench motions. This shows that the effect of a WL on subduction motions is limited by the sinking dynamics. Third, this asymptotic trend is further constrained by the fact that areas having $S^{\prime}>5 \times 10^{2}$ and $S^{\prime}<10^{-2}$ are excluded from the graph (figure $3 \mathrm{a}$ ). Such values of $S^{\prime}$ would correspond to plate-mantle and mantleWL viscosity contrasts above 500 and 1000, respectively. These are not found in nature and therefore not considered. For intermediate $S^{\prime}$ and $1 / h^{\prime}$ values, the subduction partitioning follows a co-tangential trend.

In this study, we perform simulations with varied parameters over a range that is Earth-like (figure 1b and supporting table T1. Our full set of experiments include cases where the initial viscosity of the plate and the mantle, the plate thickness and the crustal friction angle are varied to reproduce previous work (e.g., Bellahsen et al., 2005; Funiciello et al., 2008; Di Giuseppe et al., 2008), and expand upon these through the incorporation of a WL. On 
the basis of all our experiments we propose a regime diagram, which defines three distinctive subduction styles as a function of $D^{\prime}$, subduction motions $\left(V_{\mathrm{T}} / V_{\mathrm{P}} \%\right)$ and slab morphologies and dips, figure 3c. These subduction regimes are characterized by (i) a very steep slabs buckled at the mid-mantle discontinuity with advancing to quasi-stationary trenches; (ii) a relatively steep slab (but $<90^{\circ}$ ) with quasi-stationary to moderately-retreating trenches, which continue flat at the $660 \mathrm{~km}$ discontinuity; and (iii) a shallower slabs with usually fast-retreating trenches, which buoyantly tend to stagnate at the midmantle boundary (figure 3c). $D^{\prime}$ allows us to capture and constrain these three subduction styles, which characterise the deformation in the system with and without a WL, as well as most of the variety of shapes and subduction partitioning mechanisms we observe in nature. These observations support a mechanism whereby the subduction style and motions are controlled by the amount of asthenospheric drag exerted at the base of the plate.

Finally, in most of our experiments we observe a correlation between $V_{P}$ and $V_{T}$, which shows $V_{T} \pm 1 / 3 V_{P}$ (figure $3 \mathrm{~d}$ ). To test the validity of our models with relation to subduction zones on Earth, we use the estimate on $V_{P}$ and $V_{T}$ from Goes et al. (2008) for subduction zones in the Pacific plate and plot this versus our numerical experiments (figure 3d). Goes et al. (2008) uses the database of Sdrolias and Müller (2006), which is built on the Indo-Atlantic hot spots reference frame from O'Neill et al. (2005). The values of $V_{P}$ and $V_{T}$ emerging from our models mostly positively align with observed natural plate and trench migration rates. There are, however, zones that show poor correlation with our models, such as, the Tonga and Marianas trenches, which show $V_{T}> \pm 1 / 3 V_{P}$. At these localities, it is plausible that other mechanisms may be of major regional importance or coexist with the presence of a $\mathrm{WL}$, and indeed further contribute to the complexity we observe in natural systems, e.g. double subduction systems, arcuate arcs and so on. Nonetheless, at the global scale, it appears that a regional WL mechanism may play a key 
role in dictating the partitioning of plate and trench motions and offers a better match to the average $V_{T} / V_{P} \%$ values we presently observe on Earth.

\section{Discussion and conclusion}

Previous global numerical models, observations and laboratory-derived creep laws suggest a moderate bulk viscosity contrast of 1-2 orders of magnitude between the asthenosphere beneath the oceanic lithosphere and the underlying mantle (Becker, 2017; Richards \& Lenardic, 2018) and asthenosphere viscosity between $\sim 0.5 \times 10^{18}-10^{21}$ Pa.s in $\sim 200 \mathrm{~km}$ thickness (Mitrovica, 1996; Hu et al., 2016; Freed et al., 2017). Such inferred large scale asthenosphere weaknesses are generally explained by invoking the role of temperature or pressure; however, uncertainties on the true values remain, e.g. choice of appropriate rheologies and parameters. Also, the non-uniqueness relating to viscosity and thickness of an LVZ can confound the ability to distinguish between a thin layer of very low viscosity and a thick layer of greater viscosity (Cathles III, 1975; Richards \& Lenardic, 2018). Moreover, the trade-off between the resolving power and lateral extent of seismic studies may hinder the ability to distinguish narrow channels at the base of the lithosphere, such as that of a WL. Kawakatsu et al. (2009); Schmerr (2012); Naif et al. (2013); Stern et al. (2015) and Hawley et al. (2016) show that asthenospheric local and regional configurations may lead to up to a $\approx 4$ orders of magnitude meltinduced viscosity reduction into one or multiple thin and more buoyant layers at the base of the lithosphere; e.g. Hawley et al. suggests that the enhanced melt content and/or presence of hydrated phases would have significantly lubricated the base of the subducting lithosphere of the Farallon slab with potential implications for subduction motions. These asthenospheric configurations seem to be compatible with global plates and seismic anisotropy models as long as their lateral extent remains limited compared to the rest of the plate (Becker, 2017). 
In our study, we show that the presence of a thin WL at the base of the oceanic lithosphere critically affects subduction dynamics, particularly influencing the subduction speed, reducing trench migration rates and, in some cases, controlling the morphology assumed by a subducting slab. Our results show that for large viscosity contrasts $\left(\eta_{\mathrm{M}} / \eta_{\mathrm{WL}} \geq 10^{2}\right)$ and a WL thickness greater than $20 \mathrm{~km}$, the morphology of the subducting slab can be affected. In such cases, the subduction system may likely develop a quasi-stationary to an advancing moving trench with a moderate to fast convergence rate for the plate. For moderate viscosity contrasts between the mantle and the WL $\left(10^{1}<\eta_{\mathrm{M}} / \eta_{\mathrm{WL}}<10^{2}\right)$, the subduction velocity increases and trench retreat rate decreases without significantly changing the overall shape of the slab. The overall effect is reduced where thinner and more buoyant layers exist (figure $2 \mathrm{c}, \mathrm{d}$ and e, and $3 \mathrm{~b})$. This effect is constrained within end-member cases, and a description of the full range of slab behaviours is captured by the regime diagram in figure 3c. We also find that all the simulations with a WL are confined by velocity variations of a factor of $\approx 2$ maximum, and all show a low absolute subduction partitioning component, i.e. $\left|V_{\mathrm{T}} / V_{\mathrm{P}}\right|<40 \%$ (figure $3 \mathrm{a}$ and b).

The overall impact of a WL on subduction dynamics depends on the relative contrast between the effective properties of the lithosphere and the mantle. We have proposed the effective relative stiffness of the lithosphere $\left(D^{\prime}\right)$, as a diagnostic parameter for this effect. $D^{\prime}$ not only describes the results found in this study and thus the effect of a WL but also includes plate strength values, which have previously been examined in a broad range of published numerical and analogical studies (e.g., Bellahsen et al., 2005; Funiciello et al., 2008; Di Giuseppe et al., 2008). All our experiments create a comprehensive subduction regime diagram that allows one to distinguish three subduction styles as a function of the relationship between $D^{\prime}$, subduction motions $\left(V_{\mathrm{T}} / V_{\mathrm{P}} \%\right)$, and slab morphologies and dips. This characterises and constrains the defor- 
mation in the system, as well as most of the variety of shapes, velocities and trench migration mechanisms we observe in nature (figure 3c). Although our study does not exclude the potential for alternative mechanisms, the role of the effective relative stiffness of the lithosphere seems to be of significance consistently with previous studies (F. Capitanio et al., 2007; Stegman et al., 2010) and due to lithosphere-mantle decoupling processes, thus affecting trench and plate motions at subduction zones.

The setup chosen has allowed us to demonstrate that low trench retreat and fast plate speed can be the result of a simpler force balance around the subducting plate alone, whilst no extra forces or factors are needed (e.g. an overriding plate and an upper-lower mantle discontinuity); however we do not exclude that other factors which have already shown to reduce trench motions may additionally affect or coexist with the mechanism illustrated here. Nonetheless, we also employed a small number of more complicated models to explore the extent to which our simplifications may influence our conclusions (supporting figure S3-S6.). We tested the role of a VEP T-dependent rheology, which would naturally lead to weakening at the base of the lithosphere, the inclusion of the upper/lower mantle transition zone and the effect of an extended modelled box. While rheology and choice of parameters can be different, the effect of a WL shows a consistent signature.

In the literature, many models have been made to describe subduction dynamics. While these models have provided useful insights toward the modelling of natural subduction systems and mantle convection processes, the modelling of subduction zones has not yet resolved clear trends for the subduction style, convergence velocity, trench motion, and slab dip, especially in the case of slow retreating or advancing trenches in natural settings (e.g., Jarrard, 1986; Garfunkel et al., 1986; Lallemand et al., 2005; Heuret \& Lallemand, 2005; Sdrolias \& Müller, 2006; King, 2001; F. Capitanio et al., 2007). Some more recent studies have also brought considerable attention to the effect of an as- 
thenosphere of some origin in reducing trench retreat (e.g., A. F. Holt \& Becker, 2016; Billen \& Arredondo, 2018) and also enhancing plate motion when a ridge push condition is applied (e.g., F. Capitanio et al., 2007). This, along with the addition of an overriding plate to the system seems to be relevant for reducing $\left|V_{\mathrm{T}} / V_{\mathrm{P}}\right|$ observed in numerical modelling (Rodríguez-González et al., 2012; A. F. Holt et al., 2015; A. Holt et al., 2015; A. F. Holt \& Becker, 2016).

Here, we suggest that the presence of a weak upper asthenosphere underneath subducting plates in a free subduction model is already alone of importance in decreasing the high absolute values of the subduction partitioning observed in many precedent analogues and numerical models and to level more in line with the average values presently seen on Earth. Specifically, in our models the average absolute trench velocity is approximately 30 per cent or lower of the total convergence plate velocity (figure 3d), as found in many plate motion reference frames, e.g. (Schellart et al., 2008; Goscombe \& Gray, 2008; Becker \& Faccenna, 2009). Furthermore, while a maximum increase in convergence velocity of a factor of $\approx 2$ due to the weak layer is likely negligible in global models, its role becomes relevant at a regional scale influencing subduction motions and mantle flow dynamics. Thus, the regional mechanism proposed here provides a novel and explanation to interpret the apparent dichotomy in subduction partitioning values and slab dip angles globally observed along the edges of the Pacific Plate (Lallemand et al., 2005; Bellahsen et al., 2005; Coltice et al., 2017), such as the localities where the presence of a WL is confirmed by geophysical studies (e.g., Kawakatsu et al., 2009; Schmerr, 2012; Naif et al., 2013; Stern et al., 2015; Hawley et al., 2016).

\section{Acknowledgments}

We are grateful to A. Popov, A. Pusok and J. Yang for helpful discussions and inputs while at the Johannes Gutenberg University in Mainz. We thank T. Yang and other colleagues at Melbourne University for valuable comments. 
Additionally, we are grateful to two anonymous reviewers for their helpful comments. We further thank the co-authors and current code developers for providing the code Underworld2. Some computations were performed using Mogon, Raijin and Pawsey High-Performance Computing Clusters. This manuscript complies with FAIR Data standards. Software and code are open sources. We provide the DOI 10.5281/zenodo.1434224 of the 2.5.1 version of the Underworld2 code used to run our models and the DOI 10.5281/zenodo.3390014 which contains all our models scripts.

\section{References}

Anderson, D. L. (1995). Lithosphere, asthenosphere, and perisphere. Reviews of Geophysics, 33(1), 125-149.

Becker, T. W. (2017). Superweak asthenosphere in light of upper mantle seismic anisotropy. Geochemistry, Geophysics, Geosystems, 18(5), 1986-2003. doi: 10.1002/2017GC006886

Becker, T. W., \& Faccenna, C. (2009). A review of the role of subduction dynamics for regional and global plate motions. In Subduction zone geodynamics (pp. 3-34). Springer.

Becker, T. W., \& O'Connell, R. J. (2001). Predicting plate velocities with mantle circulation models. Geochemistry, Geophysics, Geosystems, $\underline{2}(12)$.

Bellahsen, N., Faccenna, C., \& Funiciello, F. (2005). Dynamics of subduction and plate motion in laboratory experiments: insights into the "plate tectonics" behavior of the earth. Journal of Geophysical Research: Solid Earth, 110(B1).

Bercovici, D. (1996). Plate generation in a simple model of lithospheremantle flow with dynamic self-lubrication. Earth and Planetary Science Letters, 144(1-2), 41-51.

Billen, M. I., \& Arredondo, K. M. (2018). Decoupling of plate- 
asthenosphere motion caused by non-linear viscosity during slab folding in the transition zone. Physics of the Earth and Planetary Interiors, 281, 17-30.

Billen, M. I., \& Hirth, G. (2007). Rheologic controls on slab dynamics. Geochemistry, Geophysics, Geosystems, $\underline{8}(8)$.

Buffett, B., \& Becker, T. (2012). Bending stress and dissipation in subducted lithosphere. Journal of Geophysical Research: Solid Earth, 117(B5).

Capitanio, F., Morra, G., \& Goes, S. (2007). Dynamic models of downgoing plate-buoyancy driven subduction: Subduction motions and energy dissipation. Earth and Planetary Science Letters, 262(1-2), 284-297.

Capitanio, F. A., Morra, G., \& Goes, S. (2009). Dynamics of plate bending at the trench and slab-plate coupling. Geochemistry, Geophysics, Geosystems, 10(4).

Cathles III, L. (1975). The viscosity of the earth's mantle princeton university press. New Jersey, 390.

Chapple, W. M., \& Tullis, T. E. (1977). Evaluation of the forces that drive the plates. Journal of geophysical research, 82(14), 19671984.

Christensen, U. R. (1996). The influence of trench migration on slab penetration into the lower mantle. Earth and Planetary Science Letters, $\underline{140}(1-4), 27-39$.

Coltice, N., Gérault, M., \& Ulvrová, M. (2017). A mantle convection perspective on global tectonics. $\quad$ Earth-Science Reviews, 165, 120-150. doi: $10.1016 /$ j.earscirev.2016.11.006

Conrad, C. P., \& Hager, B. H. (1999). Effects of plate bending and fault strength at subduction zones on plate dynamics. Journal of Geophysical Research: Solid Earth, 104(B8), 17551-17571.

Conrad, C. P., \& Lithgow-Bertelloni, C. (2002). How mantle slabs drive 
plate tectonics. Science, 298(5591), 207-209.

Crameri, F., Schmeling, H., Golabek, G., Duretz, T., Orendt, R., Buiter, S., ... Tackley, P. (2012). A comparison of numerical surface topography calculations in geodynamic modelling: An evaluation of the 'sticky air'method. Geophysical Journal International, 189(1), $38-54$.

Di Giuseppe, E., Van Hunen, J., Funiciello, F., Faccenna, C., \& Giardini, D. (2008). Slab stiffness control of trench motion: Insights from numerical models. Geochemistry, Geophysics, Geosystems, $\underline{9}(2)$.

Elsasser, W. M. (1971). Two-layer model of upper-mantle circulation. Journal of Geophysical Research, $\underline{76}(20), 4744-4753$.

Enns, A., Becker, T. W., \& Schmeling, H. (2005). The dynamics of subduction and trench migration for viscosity stratification. Geophysical Journal International, 160(2), 761-775.

Faccenna, C., Heuret, A., Funiciello, F., Lallemand, S., \& Becker, T. W. (2007). Predicting trench and plate motion from the dynamics of a strong slab. Earth and Planetary Science Letters, 257(1), 29-36.

Faccenna, C., Holt, A., Becker, T., Lallemand, S., \& Royden, L. (2017). Dynamics of the ryukyu/izu-bonin-marianas double subduction system. Tectonophysics.

Forsyth, D., et al. (1975). On the relative importance of the driving forces of plate motion. Geophysical Journal International, 43(1), 163-200.

Freed, A. M., Hashima, A., Becker, T. W., Okaya, D. A., Sato, H., \& Hatanaka, Y. (2017). Resolving depth-dependent subduction zone viscosity and afterslip from postseismic displacements following the 2011 tohoku-oki, japan earthquake. Earth and Planetary Science Letters, 459, 279-290.

Funiciello, F., Faccenna, C., Heuret, A., Lallemand, S., Di Giuseppe, E., \& Becker, T. (2008). Trench migration, net rotation and slabmantle coupling. $\quad$ Earth and Planetary Science Letters, 271(1), 
233-240.

Garel, F., Goes, S., Davies, D., Davies, J. H., Kramer, S. C., \& Wilson, C. R. (2014). Interaction of subducted slabs with the mantle transition-zone: A regime diagram from 2-d thermo-mechanical models with a mobile trench and an overriding plate. Geochemistry, Geophysics, Geosystems, 15(5), 1739-1765.

Garfunkel, Z., Anderson, C., \& Schubert, G. (1986). Mantle circulation and the lateral migration of subducted slabs. Journal of Geophysical Research: Solid Earth, 91(B7), 7205-7223.

Gerardi, G., \& Ribe, N. (2018). Boundary element modeling of two-plate interaction at subduction zones: Scaling laws and application to the aleutian subduction zone. Journal of Geophysical Research: Solid Earth, 123(6), 5227-5248.

Gerardi, G., Ribe, N. M., \& Tackley, P. J. (2019). Plate bending, energetics of subduction and modeling of mantle convection: A boundary element approach. $\quad$ Earth and Planetary Science Letters, 515, 4757.

Gérault, M., Becker, T., Kaus, B., Faccenna, C., Moresi, L., \& Husson, L. (2012). The role of slabs and oceanic plate geometry in the net rotation of the lithosphere, trench motions, and slab return flow. $\underline{\text { Geochemistry, Geophysics, Geosystems, }} \underline{13}(4)$.

Goes, S., Agrusta, R., van Hunen, J., \& Garel, F. (2017). Subductiontransition zone interaction: A review. Geosphere, 13(3), 644-664.

Goes, S., Capitanio, F., Morra, G., Seton, M., \& Giardini, D. Signatures of downgoing plate-buoyancy driven subduction in cenozoic plate motions. $\quad$ Physics of the Earth and Planetary Interiors, $\underline{184}(1-2), 1-13$.

Goes, S., Capitanio, F. A., \& Morra, G. (2008). Evidence of lower-mantle slab penetration phases in plate motions. Nature, $\underline{451}(7181), 981$.

Goscombe, B. D., \& Gray, D. R. (2008). Structure and strain variation at 
mid-crustal levels in a transpressional orogen: a review of kaoko belt structure and the character of west gondwana amalgamation and dispersal. Gondwana Research, 13(1), 45-85.

Harper, J. F. (1975). On the driving forces of plate tectonics. Geophysical Journal International, 40(3), 465-474.

Hawley, W. B., Allen, R. M., \& Richards, M. A. (2016). Tomography reveals buoyant asthenosphere accumulating beneath the juan de fuca plate. Science, 353(6306), 1406-1408.

Heuret, A., \& Lallemand, S. (2005). Plate motions, slab dynamics and back-arc deformation. Physics of the Earth and Planetary Interiors, 149(1-2), 31-51.

Höink, T., Jellinek, A. M., \& Lenardic, A. (2011). Viscous coupling at the lithosphere-asthenosphere boundary. Geochemistry, Geophysics, Geosystems, 12(10).

Höink, T., Lenardic, A., \& Richards, M. (2012). Depth-dependent viscosity and mantle stress amplification: implications for the role of the asthenosphere in maintaining plate tectonics. Geophysical Journal International, 191(1), 30-41.

Holt, A., Becker, T., \& Buffett, B. (2015). Trench migration and overriding plate stress in dynamic subduction models. Geophysical Journal International, 201(1), 172-192.

Holt, A., Royden, L., \& Becker, T. (2017). The dynamics of double slab subduction. Geophysical Journal International, 209(1), 250-265.

Holt, A. F., \& Becker, T. W. (2016). The effect of a power-law mantle viscosity on trench retreat rate. Geophysical Journal International, ggw392.

Holt, A. F., Buffett, B. A., \& Becker, T. W. (2015). Overriding plate thickness control on subducting plate curvature. Geophysical $\underline{\text { Research Letters, }} \underline{42}$ (10), 3802-3810.

Hu, Y., Bürgmann, R., Banerjee, P., Feng, L., Hill, E. M., Ito, T., ... 
Wang, K. (2016). Asthenosphere rheology inferred from obser-

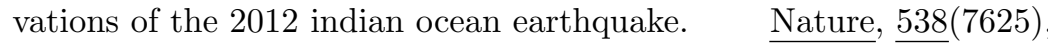
368.

Jarrard, R. D. (1986). Relations among subduction parameters. Reviews of Geophysics, 24(2), 217-284.

Kawakatsu, H., Kumar, P., Takei, Y., Shinohara, M., Kanazawa, T., Araki, E., \& Suyehiro, K. (2009). Seismic evidence for sharp lithosphere-asthenosphere boundaries of oceanic plates. Science, 324(5926), 499-502.

King, S. D. (2001). Subduction zones: observations and geodynamic models. Physics of the Earth and Planetary Interiors, 127(1-4), 9-24.

Lallemand, S., Heuret, A., \& Boutelier, D. (2005). On the relationships between slab dip, back-arc stress, upper plate absolute motion, and crustal nature in subduction zones. Geochemistry, Geophysics, Geosystems, 6(9).

Lithgow-Bertelloni, C., \& Richards, M. A. (1995). Cenozoic plate driving forces. Geophysical Research Letters, 22(11), 1317-1320.

Lithgow-Bertelloni, C., \& Richards, M. A. (1998). The dynamics of cenozoic and mesozoic plate motions. Reviews of Geophysics, 36(1), 2778.

Mitrovica, J. X. (1996). Haskell [1935] revisited. Journal of Geophysical Research: Solid Earth, 101(B1), 555-569.

Mitrovica, J. X., \& Forte, A. M. (1997). Radial profile of mantle viscosity: results from the joint inversion of convection and postglacial rebound observables. Journal of Geophysical Research: Solid Earth (1978-2012), 102(B2), 2751-2769.

Moresi, L., \& Gurnis, M. (1996). Constraints on the lateral strength of slabs from three-dimensional dynamic flow models. Earth and $\underline{\text { Planetary Science Letters, }}$ 138(1-4), 15-28.

Moresi, L., Quenette, S., Lemiale, V., Meriaux, C., Appelbe, B., \& 
Mühlhaus, H.-B. (2007). Computational approaches to studying non-linear dynamics of the crust and mantle. Physics of the Earth and Planetary Interiors, $163(1-4), 69-82$.

Moresi, L., \& Solomatov, V. (1998). Mantle convection with a brittle lithosphere: thoughts on the global tectonics styles of the Earth and Venus. Geophysical Journal International, 133, 669-682.

Morgan, W. J. (1971). Convection plumes in the lower mantle. Nature, $230(5288), 42-43$.

Morgan, W. J. (1972). Deep mantle convection plumes and plate motions. AAPG bulletin, 56(2), 203-213.

Naif, S., Key, K., Constable, S., \& Evans, R. (2013). Melt-rich channel observed at the lithosphere-asthenosphere boundary. Nature, 495(7441), 356-359.

O’Neill, C., Müller, D., \& Steinberger, B. (2005). On the uncertainties in hot spot reconstructions and the significance of moving hot spot reference frames. Geochemistry, Geophysics, Geosystems, 6(4).

Phipps Morgan, J., Morgan, W. J., Zhang, Y.-S., \& Smith, W. H. (1995). Observational hints for a plume-fed, suboceanic asthenosphere and its role in mantle convection. Journal of Geophysical Research: Solid Earth, 100(B7), 12753-12767.

Ribe, N. (2001). Bending and stretching of thin viscous sheets. Journal of Fluid Mechanics, 433, 135-160.

Ribe, N. M. (1992). The dynamics of thin shells with variable viscosity and the origin of toroidal flow in the mantle. Geophysical Journal $\underline{\text { International, }} \underline{110}(3), 537-552$.

Ribe, N. M. (2010). Bending mechanics and mode selection in free subduction: A thin-sheet analysis. Geophysical Journal International, $\underline{180}(2), 559-576$

Richards, M. A., \& Lenardic, A. (2018). The cathles parameter (ct): A geodynamic definition of the asthenosphere and implications for the 
nature of plate tectonics. Geochemistry, Geophysics, Geosystems, 19(12), 4858-4875.

Rodríguez-González, J., Negredo, A. M., \& Billen, M. I. (2012). The role of the overriding plate thermal state on slab dip variability and on the occurrence of flat subduction. Geochemistry, Geophysics, Geosystems, 13(1).

Royden, L. H., \& Husson, L. (2006). Trench motion, slab geometry and viscous stresses in subduction systems. Geophysical Journal International, $\underline{167}(2), 881-905$.

Sakamaki, T., Suzuki, A., Ohtani, E., Terasaki, H., Urakawa, S., Katayama, Y., ... Ballmer, M. D. (2013). Ponded melt at the boundary between the lithosphere and asthenosphere. Nature Geoscience, 6(12), 1041-1044.

Schellart, W. (2004). Quantifying the net slab pull force as a driving mechanism for plate tectonics. Geophysical Research Letters, 31(7).

Schellart, W., Freeman, J., Stegman, D., Moresi, L., \& May, D. (2007). Evolution and diversity of subduction zones controlled by slab width. Nature, 446(7133), 308-311.

Schellart, W., Stegman, D., Farrington, R., Freeman, J., \& Moresi, L. (2010). Cenozoic tectonics of western north america controlled by evolving width of farallon slab. Science, 329(5989), 316-319.

Schellart, W., Stegman, D., \& Freeman, J. (2008). Global trench migration velocities and slab migration induced upper mantle volume fluxes: Constraints to find an earth reference frame based on minimizing viscous dissipation. Earth-Science Reviews, 88(1), 118-144.

Schmeling, H., Babeyko, A., Enns, A., Faccenna, C., Funiciello, F., Gerya, T., ... others (2008). A benchmark comparison of spontaneous subduction models - towards a free surface. Physics of the Earth and Planetary Interiors, $171(1), 198-223$.

Schmerr, N. (2012). The gutenberg discontinuity: Melt at the lithosphere- 
asthenosphere boundary. Science, 335(6075), 1480-1483.

Sdrolias, M., \& Müller, R. D. (2006). Controls on back-arc basin formation. Geochemistry, Geophysics, Geosystems, $7(4)$.

Semple, A. G., \& Lenardic, A. (2018). Plug flow in the earth's asthenosphere. Earth and Planetary Science Letters, 496, 29-36.

Stegman, D., Farrington, R., Capitanio, F., \& Schellart, W. (2010). A regime diagram for subduction styles from 3-d numerical models of free subduction. Tectonophysics, $\underline{483}(1), 29-45$.

Stegman, D., Freeman, J., Schellart, W., Moresi, L., \& May, D. (2006). Influence of trench width on subduction hinge retreat rates in 3-d models of slab rollback. Geochemistry, Geophysics, Geosystems, $7(3)$.

Stern, T., Henrys, S., Okaya, D., Louie, J., Savage, M., Lamb, S., ... Iwasaki, T. (2015). A seismic reflection image for the base of a tectonic plate. Nature, 518(7537), 85-88.

Tackley, P. J. (2000). Self-consistent generation of tectonic plates in time-dependent, three-dimensional mantle convection simulations. Geochemistry, Geophysics, Geosystems, 1(8).

Wu, B., Conrad, C. P., Heuret, A., Lithgow-Bertelloni, C., \& Lallemand, S. (2008). Reconciling strong slab pull and weak plate bending: The plate motion constraint on the strength of mantle slabs. Earth and $\underline{\text { Planetary Science Letters, }}$ 272(1-2), 412-421.

Yamato, P., Husson, L., Braun, J., Loiselet, C., \& Thieulot, C. (2009). Influence of surrounding plates on $3 \mathrm{~d}$ subduction dynamics. Geophysical Research Letters, $\underline{36}(7)$.

Yang, T., Gurnis, M., \& Zhan, Z. (2017). Trench motion-controlled slab morphology and stress variations: Implications for the isolated 2015 bonin islands deep earthquake. Geophysical Research Letters.

Zhong, S., \& Davies, G. F. (1999). Effects of plate and slab viscosities on the geoid. Earth and Planetary Science Letters, 170(4), 487-496. 
Zhong, S., \& Gurnis, M. (1997). Dynamic interaction between tectonic plates, subducting slabs, and the mantle. Earth Interactions, $\underline{1}(3)$, $1-18$.

Zhong, S., Gurnis, M., \& Moresi, L. (1998). Role of faults, nonlinear rheology, and viscosity structure in generating plates from instantaneous mantle flow models. Journal of Geophysical Research: Solid Earth, 103(B7), 15255-15268. 


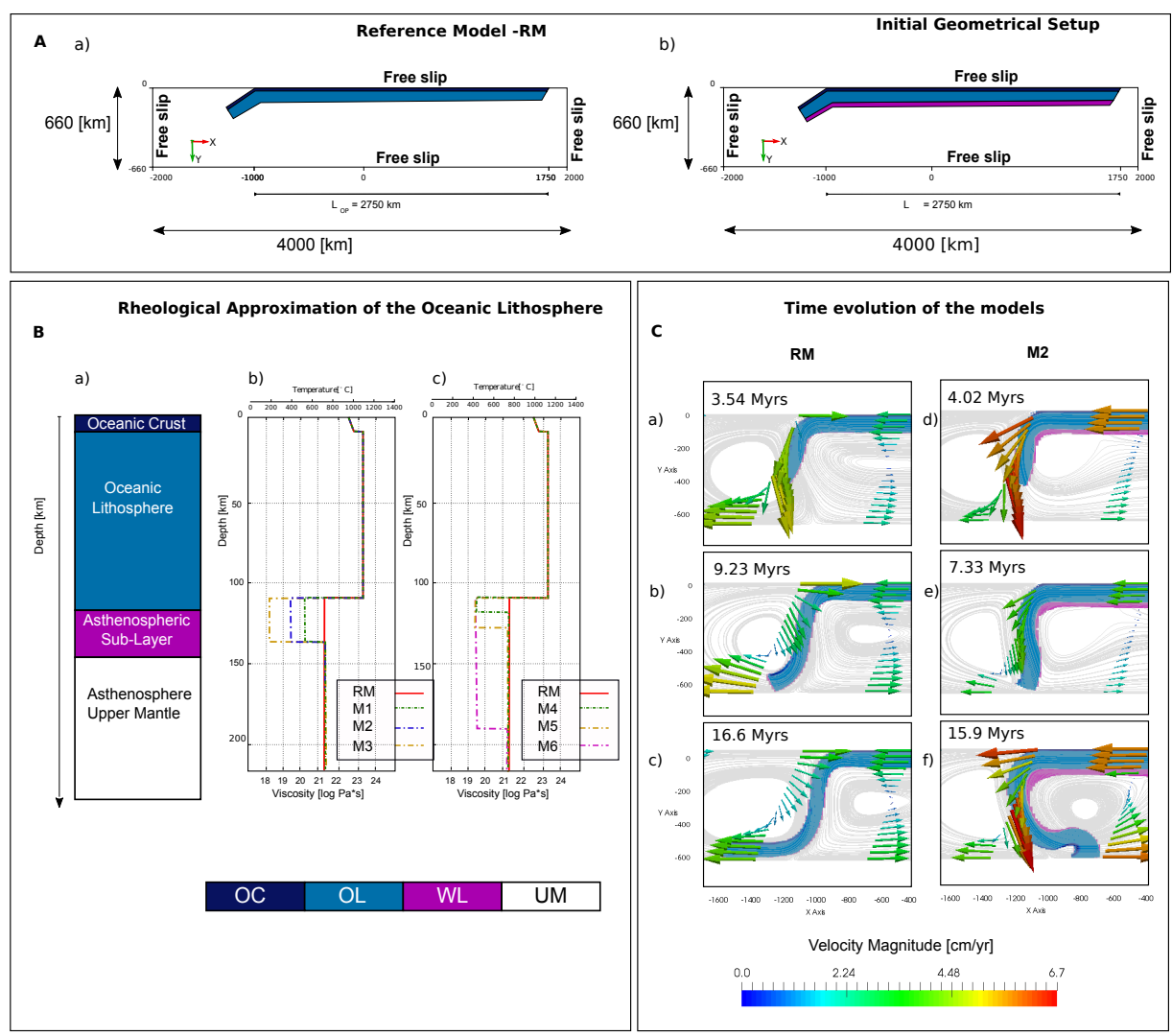

Figure 1. A shows a schematic representation of the geometrical setup for the reference model (RM) and the models with a weak layer (WL) in a and b, respectively. B shows the material field in a, the initial rheological setup for the pseudo-plastic (PP) with different viscosity contrast mantle and WL in b and WL thickness in c. C shows the subduction time evolution in a comparison between the RM and a model with a WL $\left(\mathrm{M} 2, \eta_{\mathrm{M}} / \eta_{\mathrm{WL}}=100\right)$. 


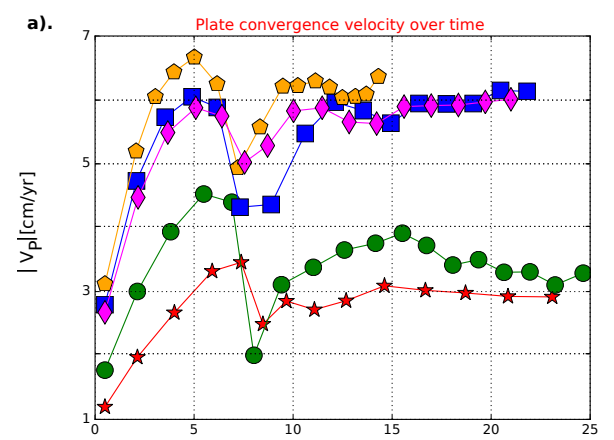

d).
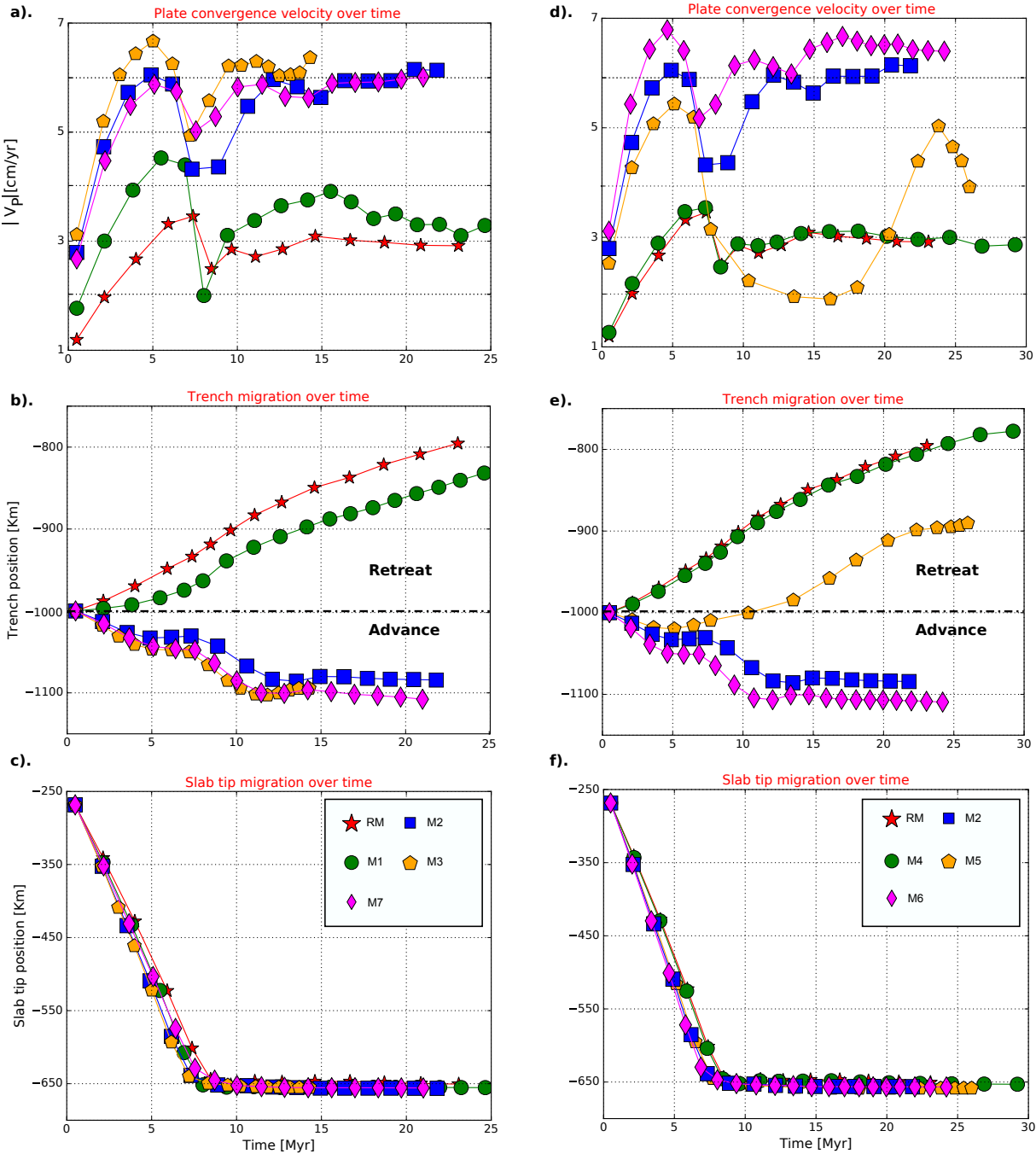

Figure 2. Evolution of plate velocities $\left(V_{P}\right)$, trench and slab tip migrations through time, for a progressive increase in $\eta_{\mathrm{M}} / \eta_{\mathrm{WL}}$ and $\Delta \rho_{(\mathrm{M}-\mathrm{WL})}$, and in $h_{\mathrm{WL}}$, as seen in a, b, c and d, e, f, respectively. 

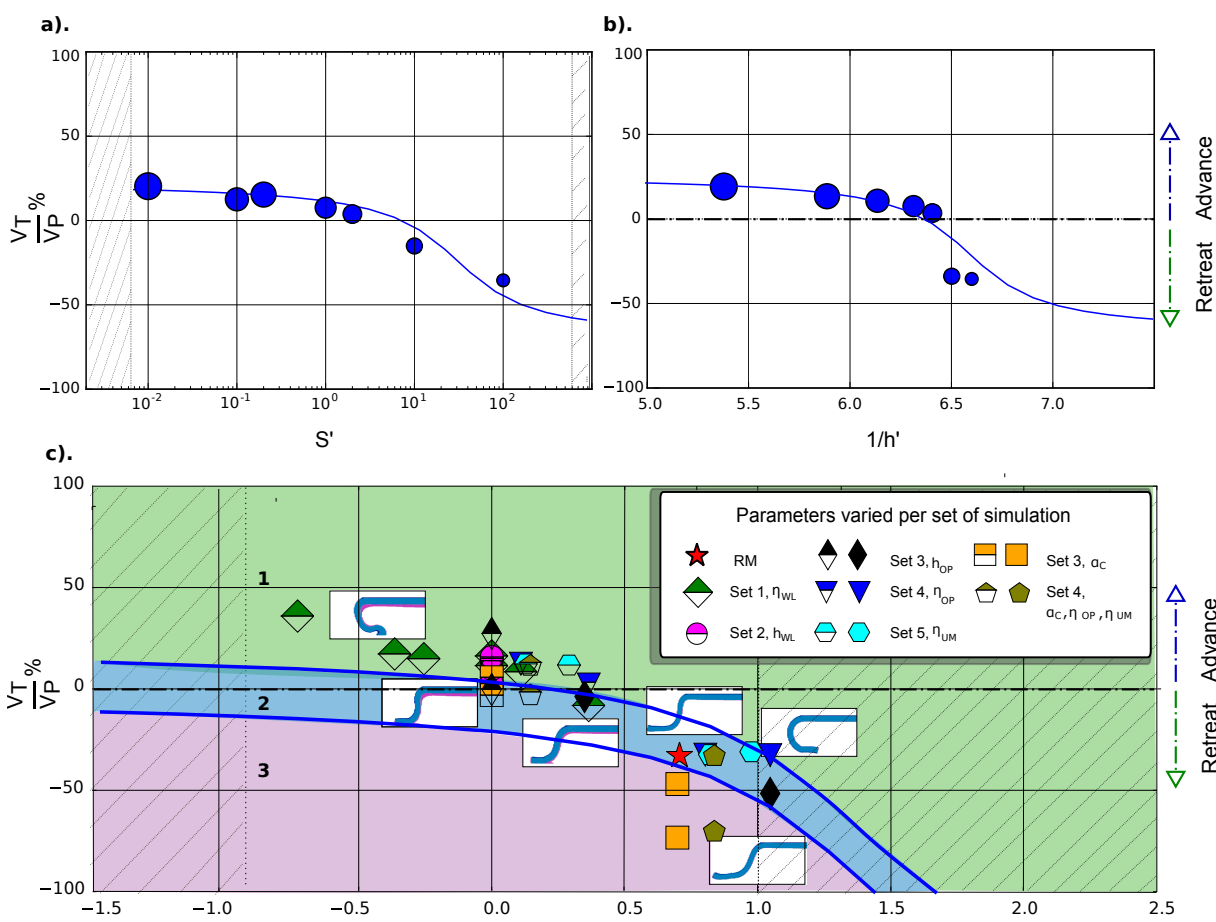

d).

$D^{\prime}$

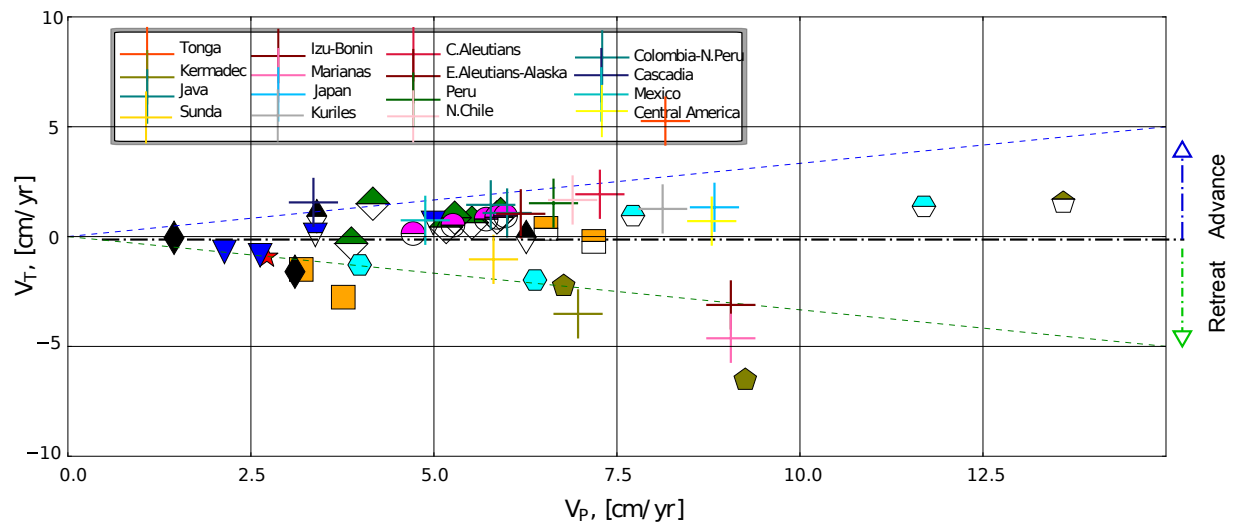

Figure 3. shows in a and $\mathrm{b}$ the subduction partitioning $\left(V_{T} / V_{P} \%\right)$ as a function of the effective relative strength $\left(S^{\prime}\right)$ and thickness $\left(h^{\prime}\right)$ of the lithosphere for a progressively weaker or thinner WL, respectively. The values for each simulation are plotted using a scatter plot function of $S^{\prime}$ and $h^{\prime}$ in a and b, respectively. Figure c shows variations in $V_{T} / V_{P} \%$ with respect to the effective relative stiffness of the lithosphere $\left(D^{\prime}\right)$ for all the simulations performed in this study. The different coloured fields define the three areas having different subduction styles. d shows the relationship between $V_{P}$ and trench velocity $V_{T}$, as found in our experiments and in natural cases (Goes et al., 2011). The majority of the points lies between the dotted lines $\left(V_{T}=m V_{P}\right)$ having $m$ equal to $\pm 1 / 3$. 


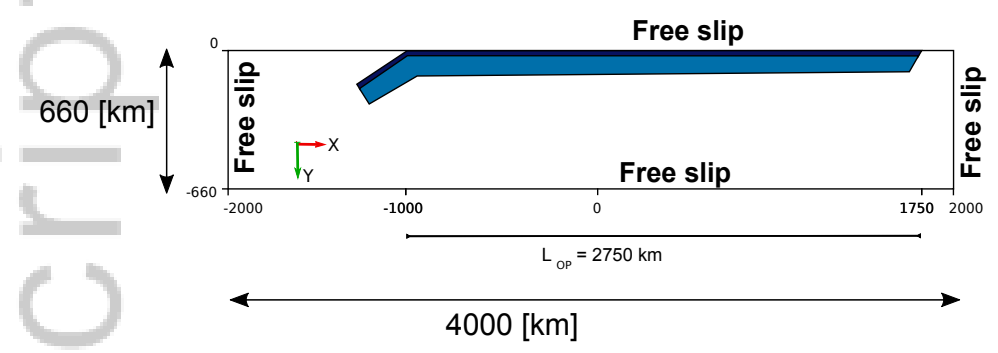

b)
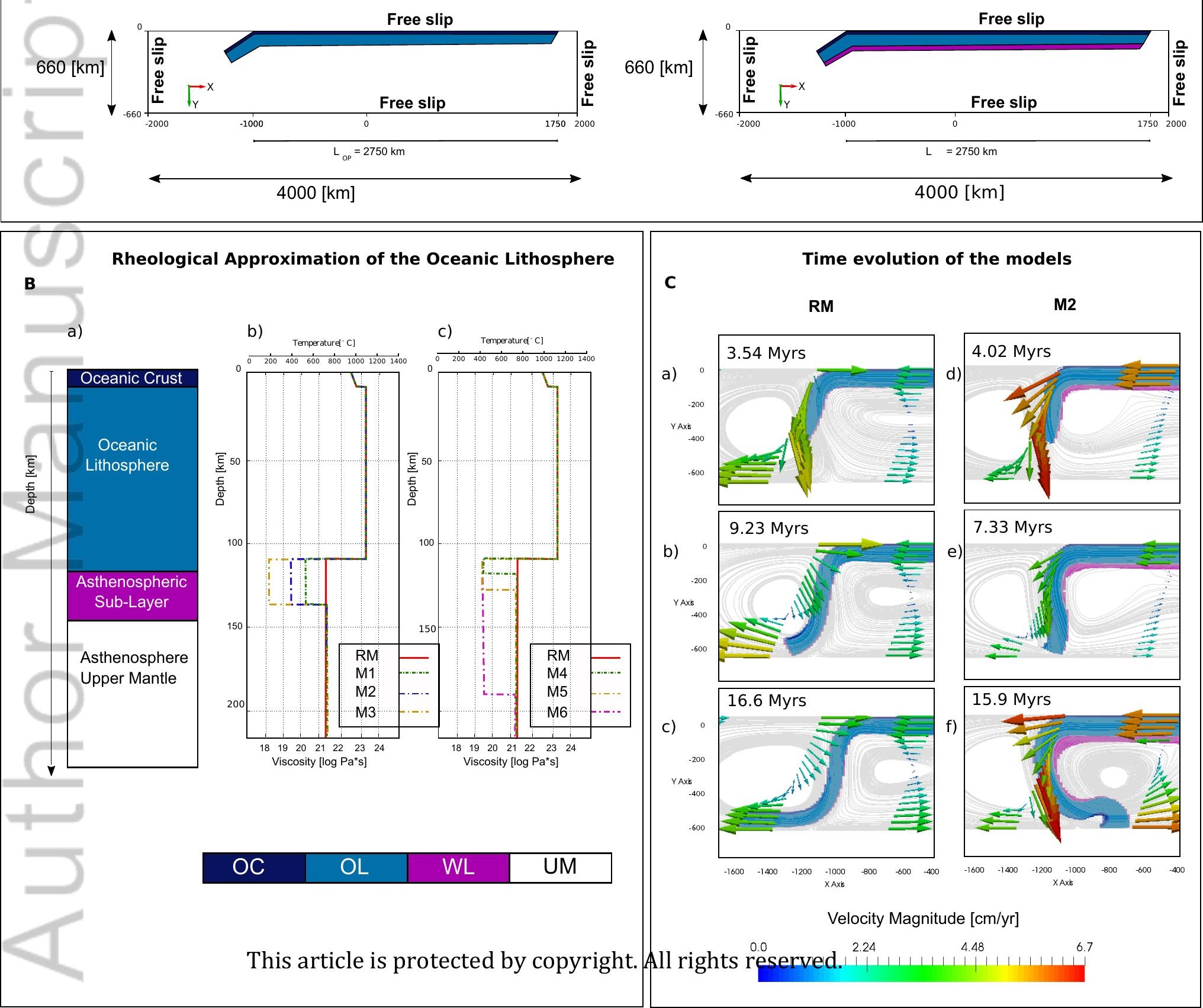

This article is protected by copyright. 


\section{University Library}

\section{- M M N E R VA A gateway to Melbourne's research publications}

Minerva Access is the Institutional Repository of The University of Melbourne

Author/s:

Carluccio, R;Kaus, B;Capitanio, FA;Moresi, LN

Title:

The Impact of a Very Weak and Thin Upper Asthenosphere on Subduction Motions

Date:

2019-11-11

Citation:

Carluccio, R., Kaus, B., Capitanio, F. A. \& Moresi, L. N. (2019). The Impact of a Very Weak and Thin Upper Asthenosphere on Subduction Motions. GEOPHYSICAL RESEARCH LETTERS, 46 (21), pp.11893-11905. https://doi.org/10.1029/2019GL085212.

Persistent Link:

http://hdl.handle.net/11343/286595 